\title{
Jornalismo de saúde: novos rumos, novas literacias
}

Ana Paula Margarido de Azevedo*

Resumo: O terramoto no Haiti, ocorrido em Janeiro de 2010, levantou uma importante discussão deontológica nas áreas da comunicação e da saúde. Algumas perguntas emergiram a partir deste acidente, tais como: o que acontece quando médicos e jornalistas são a mesma pessoa? Que princípios éticos devem cumprir aqueles que exercem as duas funções? Embora não tenham sido esgotadas, essas questões foram devida e amplamente debatidas por estudiosos da comunicação, jornalistas e profissionais de saúde. Pouco se discutiu, neste contexto, sobre a formação do jornalista de saúde e o tipo de literacias que são necessárias para que ele desempenhe as suas tarefas com rigor na cobertura de notícias de saúde. Neste sentido, este ensaio pretende estabelecer um debate sobre a necessidade ou não de formação específica para o exercício responsável do jornalismo de saúde, desempenhado por profissionais da comunicação social, e como essas habilidades se reflectem no fortalecimento das literacias dos leitores.

Palavras-chave: jornalismo de saúde, literacia, comunicação na saúde.

\section{Introdução}

Nos últimos anos tem-se assistido a uma crescente "desintermediação" profissional do acesso às informações de saúde. Como consequência da globalização, a democratização do acesso à informação, através das novas tecnologias, tem um grande peso nesse fenómeno, pois ela permite não apenas que os leitores acedam directamente aos conteúdos desejados mas, também, que criem mensagens sobre qualquer área do conhecimento. A presença das tecnologias de comunicação e informação tem trazido modificações no modo de fazer o jornalismo em geral e, muito particularmente, o jornalismo de saúde.

De facto, a presença destes "ventos cruzados" (Pinto, 2004) sobre a profissão do jornalista já tinha sido observada nas investigações sobre o campo jornalístico e sugere tanto

\footnotetext{
*Universidade do Minho (anamargarido@gmail.com).
} 
uma mudança da percepção do jornalista relativamente ao exercício da profissão como a necessidade de um debate mais aprofundado sobre as transformações impostas.

No que se refere à informação da saúde veiculada nos meios de massa, nomeadamente através do jornalismo, tem-se notado uma tendência de restituição aos profissionais da saúde, sobretudo médicos e psicólogos, a responsabilidade pela divulgação e promoção dos temas relacionados com essa área no campo da comunicação social, nomeadamente na ancoragem de programas sobre medicina, saúde e comportamento, mas também como repórteres e escritores de colunas dedicadas à saúde.

Verificam-se, assim, processos de alteração do papel do jornalista de saúde enquanto “corrector das informações de saúde” (Hinnant \& Len-Rios, 2009), pois ele não é mais o único a intermediar o acesso do público leigo às informações de saúde veiculadas nos meios de comunicação social.

O terramoto de magnitude 7 , que matou duzentas mil pessoas e deixou outras trezentas mil feridas, em Porto Príncipe, capital do Haiti, e que devastou outras localidades haitianas, em Janeiro de 2010 (G1, 2010), serviu, durante e depois da cobertura do desastre, como pano de fundo para discussões de foro ético e deontológico de médicos e jornalistas, colocando em questão o desempenho simultâneo das duas funções pelo mesmo profissional na figura do médico-repórter.

O desempenho de duplas funções não é, de resto, um fenómeno novo. Era, aliás, um procedimento comum adoptado em várias redacções nos anos 50 . No pós-guerra, os médicos-jornalistas trabalhavam como "correspondentes de saúde”, embora tivessem pouco ou nenhum treino no campo jornalístico (Berridge, 2007).

Os anos dourados, marcados pelos grandes avanços na área tecnológica, pelo desenvolvimento cultural e científico acentuado e pelo início das transmissões de televisão, foram também um marco no jornalismo de saúde europeu. Uma das primeiras manifestações deste campo na Europa aconteceu por volta da década de 50, com uma médica francesa que mantinha uma coluna semanal dirigida aos médicos no diário francês $L e$ Monde. Apesar de escrever para colegas de profissão, os temas por ela levantados eram de relevante interesse popular. Tal facto iria consolidar, anos mais tarde, na França da década de 70, a figura do doutor-jornalista (Favereau, 2005).

Não é, de todo, nosso intuito questionar a qualidade do trabalho realizado pelos profissionais de saúde na área da comunicação, embora esse seja também um aspecto pertinente neste debate. A questão subjacente aos processos de "desintermediação" do acesso às informações de saúde, e sobre a qual queremos reflectir, baseia-se no tipo de competências que os profissionais da comunicação social responsáveis pela cobertura de saúde devem aceder, para executarem as suas tarefas e melhorarem o conhecimento do público sobre saúde.

$\mathrm{O}$ que se pretende neste ensaio, portanto, é ampliar a polémica emergida com o digamos ressurgimento do debate sobre o "médico-repórter", colocando a ênfase na formação do jornalista de saúde, desde já definido “como repórter, escritor ou editor que cobre notícias médicas e questões de saúde pública e pessoal”(Hinnant \& Len-Rios, 2009). O nosso principal objectivo é verificar que literacias são exigidas para que o jornalista responsável pela cobertura de notícias ligadas às ciências médicas e à saúde 
desempenhe as suas tarefas com rigor. E, para além disso, contribua para formar cidadãos mais críticos e responsáveis no campo da saúde.

Optámos por um debate teórico que busca, por um lado, enquadrar as definições de comunicação da saúde, jornalismo de saúde e literacia mediática, numa perspectiva de responsabilização, e, por outro, verificar como essas habilidades concorrem também para aumentar a literacia do público/consumidor de informação de saúde.

$\mathrm{O}$ texto divide-se em quatro partes e uma conclusão. A primeira procura encontrar o lugar dos média em geral e do jornalismo de saúde, em particular, enquanto promotores de saúde, dentro do conceito de comunicação da saúde; a segunda busca identificar as possíveis falhas que ocorrem no processo de promoção da saúde através das notícias sobre este tema; uma terceira parte contempla a formação do jornalista de saúde, enfatizando a questão das multiliteracias; e a quarta parte busca associar as competências do jornalista de saúde às competências do público no que diz respeito ao uso das informações de saúde para melhorar o seu conhecimento nesta área.

\section{O jornalismo na comunicação da saúde}

A comunicação em saúde desenvolve-se em vários níveis: interpessoal, organizacional, comunitário e nos mass media (Thomas, 2006). No que diz respeito ao papel dos meios de massa, tem-se observado um certo consenso nas definições de comunicação da saúde ${ }^{1}$.

Para além da parceria nas campanhas institucionais de saúde pública, estrategicamente utilizada pelas autoridades de saúde para comunicar riscos, prevenir doenças e promover a saúde, os média têm garantido a circulação da informação médica e de saúde através de diversos meios e canais: da publicidade privada, do marketing, dos sítios web públicos e privados, dos fóruns de discussão online e chats, do jornalismo tradicional e online, dos blogues e outros.

Aos meios tradicionais como a televisão, a rádio, os jornais, as revistas e os outdoors acrescem agora o computador e outros dispositivos tecnológicos de comunicação móvel, como os telemóveis e os iphones, através dos quais a Internet e os aplicativos proporcionam o acesso rápido e personalizado às informações de saúde.

Mas, se por um lado os média interactivos, tal como a internet, têm demonstrado vantagens em relação aos média tradicionais, melhorando o acesso à informação personalizada de saúde e aos serviços e demandas de saúde, bem como ampliando as escolhas dos consumidores, por outro lado, a televisão e a rádio têm permanecido como meios estratégicos para a promoção da saúde e prevenção de doenças.

Ao ligar as áreas da comunicação e da saúde, a comunicação em saúde, campo de pesquisas que ganhou força nos anos 80 , tem sido considerada cada vez mais necessária para melhorar a saúde pública e individual.

\footnotetext{
1 Deixamos de lado o debate no campo semântico sobre a melhor tradução para o termo Health Communication, que poderia ser definido como comunicação da saúde, comunicação em saúde ou, ainda, comunicação na saúde. Assumimos as consequências de usar as terminologias indiscriminadamente neste texto.
} 
O Centro Europeu para a Prevenção e Controlo de Doenças ${ }^{2}$ descreve a comunicação em saúde como uma componente vital da prática da saúde e relaciona-a com conceitos complementares, tais como a literacia da saúde, a educação para a saúde, o marketing social, a comunicação de risco e a comunicação de crises.

Uma vez que indagamos as competências básicas para o exercício da função de jornalista, com ênfase na cobertura noticiosa na área de saúde, é oportuno distinguir, aqui, literacia de saúde, que é definida como a capacidade que cada indivíduo tem para aceder e usar efectivamente as informações relacionadas com a saúde, de educação para a saúde, que por sua vez, tem sido conceptualizada como o objectivo de influenciar de forma positiva o conhecimento, as atitudes e o comportamento associados à saúde.

De acordo com o relatório do Departamento de Saúde norte-americano (HHS), Health People 2010, a comunicação da saúde engloba o estudo e o uso de estratégias de comunicação para formar e influenciar decisões individuais e comunitárias que fortaleçam a saúde.

A comunicação em saúde também tem sido entendida como um campo de tensões (Thompson, Dorsey, Miller \& Parrott, 2003) e, em alguns casos, como sinónimo de informação em saúde (Niederdeppe, Farrelly, Thomas, Wenter \& Weitzenkamp, 2007).

A definição proposta por Schiavo (2007) de comunicação em saúde resume, de certa forma, os conceitos que explicitamos neste ensaio. De acordo com essa autora, a comunicação na saúde deve ser entendida como uma abordagem multifacetada e multidisciplinar que visa atingir diversas audiências e partilhar informações relacionadas com a saúde com o objectivo de influenciar, engajar e apoiar [os diversos actores sociais] indivíduos, comunidades, profissionais de saúde, grupos especiais, legisladores e o público no sentido de introduzir, adoptar um comportamento, prática ou política que, em última análise, melhorem os resultados de saúde.

Assim, os média têm sido considerados meios importantes para transmitir mensagens de saúde às populações, não só por atingirem um elevado número de pessoas, como também por chegarem justamente àqueles que, de outro modo, mais dificuldades teriam em lhes aceder, quer pelo contacto com profissionais de saúde quer pela educação formal.

No contexto acima descrito, os média são designados como parceiros estratégicos tanto para melhorar a literacia de saúde como para aumentar os resultados na educação para a saúde.

$\mathrm{Na}$ história da comunicação da saúde, no entanto, pelo menos no que diz respeito às campanhas de saúde pública, o jornalismo tem desempenhado um papel coadjuvante enquanto campo estratégico para influenciar comportamentos e atitudes individuais e colectivas. O protagonismo nesta área tem sido delegado principalmente no marketing, um dos responsáveis pelo crescimento da comunicação em saúde como campo de estu$\operatorname{dos}^{3}$ (Thomas, 2006).

\footnotetext{
${ }^{2}$ European Centre for Disease Prevention and Control.

3 Thomas (2006) também refere a crescente preocupação das pessoas com a saúde e a transformação da indústria dos cuidados de saúde numa das maiores indústrias em meados do século XX como factores que contribuíram para a emergência da comunicação em saúde como campo de estudos.
} 
Nas campanhas de saúde pública de maior sucesso nos Estados Unidos, por exemplo, o jornalismo veio, na maioria das vezes, a reboque das acções de marketing e da publicidade. Nos últimos anos, novelas e programas de entretenimento têm servido como estratégia para promover a saúde, mais que o jornalismo.

No entanto, as notícias são, muitas vezes, a primeira, senão a única, fonte de informação científica para a maioria das pessoas (Nelkin, 1996), e, nesse sentido, devem ser consideradas importantes canais para comunicar a saúde. Diversas pesquisas ${ }^{4}$ mostram que é cada vez maior o interesse das pessoas pelas informações de saúde divulgadas na imprensa.

In the National Health Council's survey 75 per cent of the 2256 persons interviewed in the United States paid either substantial ( 25 per cent) or average ( 50 per cent) attention to medical and health-related news in the media. (Ginman, 2000)

Para além disso, actualmente o jornalismo de saúde tem contribuído de um modo muito mais frequente para manter na agenda pública temas relacionados com a saúde pública e individual, alertar para determinados tipos de risco e de comportamento e reforçar processos de mudança. Assim, é de sublinhar que o jornalismo de saúde, através do agendamento, cumpre a importante tarefa de manter os temas das campanhas de saúde visíveis. Além disso, é por meio das notícias que a opinião pública é formada e, depois, incorporada na sociedade.

Lembramos, por exemplo, que a cobertura intensa feita pelos grandes média norte-americanos contribuiu de maneira significativa para o sucesso de uma das maiores campanhas contra o uso de drogas nos Estados Unidos, que envolveu a primeira-dama de então, Nancy Reagan. Através dos jornais, a frase "Just say no", que Nancy Reagan deu como resposta a uma aluna que lhe perguntara o que fazer quando lhe oferecessem droga, tornou-se uma das mais conhecidas e usadas expressões na luta contra as drogas, nas décadas de 80 e 90, nos Estados Unidos da América.

Pelo menos dois factores bastante relevantes concorrem para essa marginalidade do jornalismo de saúde de que falamos na comunicação da saúde. O primeiro tem a ver com a noção de que canais como a publicidade e o marketing são mais persuasivos (Flora, Maibach, \& Maccoby, 1989) e produzem os efeitos desejados num menor espaço de tempo. O segundo prende-se com a própria natureza do jornalismo e com o modo como ele tem sido desempenhado na cobertura de saúde.

Niederdeppe et al. (2007) observaram, por exemplo, que "a cobertura noticiosa das campanhas de saúde pública representava uma possível fonte de efeitos indirectos nos receptores, pois tanto o volume quanto o conteúdo das notícias não tinham o controlo directo dos planeadores da campanha” (p. 382). Para além disso, a compreensibilidade da informação, como de forma a assegurar que as mensagens sejam inteiramente entendidas pelos membros da audiência pretendida, é um dos mais relevantes critérios da comunicação em saúde (Thompson et al., 2003).

\footnotetext{
${ }^{4}$ O relatório da UMIC (A Sociedade da Informação em Portugal, 2010) mostra que tem aumentado o interesse dos portugueses por informações na área da saúde, nomeadamente, sobre medicamentos, obesidade e cuidados de saúde.
} 
De facto, existe uma grande preocupação dos profissionais de saúde, cientistas e autoridades com o rigor das matérias jornalísticas nesta área. Então, vejamos.

\section{Falhas e acertos na cobertura jornalística de saúde}

Desde que, por volta da década de 80, empresários da comunicação e também da área da saúde perceberam que se poderia fazer negócio com a saúde (Johnson, 1998), que este campo se tornou estratégico na área da comunicação (Kuscinsky, 2002).

Os anos 80 podem, aliás, ser considerados uma época áurea para o campo da comunicação em saúde. Datam dessa altura alguns acontecimentos que marcaram este campo. No âmbito sociocultural, temos, por um lado, o crescimento da preocupação individual com o corpo e com a aparência física, caracterizada pela cultura do self; por outro, temos o aumento dos registos de casos de sida e de consumo de drogas. No campo científico, a intensificação dos estudos a unir as áreas de comunicação e de saúde culminou na criação da revista Health Communication, a primeira a reunir de forma sistemática pesquisas na área da comunicação em saúde. No campo político, realizou-se, no Canadá, a primeira reunião para definir estratégias comuns entre diversos países com o objectivo de melhorar a saúde mundial. O conjunto dessas estratégias foi reunido na conhecida Carta de Otava, na qual os média são reconhecidos como parceiros na promoção da saúde.

Ora, numa perspectiva normativa, o jornalismo de referência deve-se guiar pelos princípios da liberdade, da igualdade e da objectividade (McQuail, 2003). Entretanto, inúmeras críticas que envolvem a inobservância desses critérios têm sido dirigidas ao jornalismo de saúde. Do ponto de vista das competências, algumas reclamações recaem sobre a formação do jornalista, que, na visão dos analistas, não é suficiente para o desempenho crítico da profissão.

Alguns autores argumentam que a cobertura jornalística de saúde tem resvalado, até de forma sistemática, para o sensacionalismo, a banalização, a parcialidade e a imperícia dos temas cobertos (Johnson, 1998; Seale, 2002; Shuchman \& Wilkes, 1997; Shwitzer, 2008).

Como exemplo, reproduzimos alguns dos problemas enumerados por Shuchman \& Wilkes (1997):

1. Foco reduzido: durante toda a semana, os jornalistas são confrontados com uma avalanche de press-releases que, em lugar de abrir o espaço para a diversidade, acaba por os desencorajar na busca de outros temas;

2. informações mal explicadas: os cientistas não detalham as informações como deveriam, com medo de que os jornalistas não as compreendam;

3. cobertura reduzida: há muitos temas que, mesmo considerados importantes, não entram na pauta das redacções.

De facto, análises comparativas feitas em jornais norte-americanos (Pellechia, 1997), brasileiros e portugueses (Azevedo, 2009), holandeses (Hijmans, Pleijter \& Wester, 2003) e neozelandeses (Hodgetts, Chamberlain, Scammel, Karapu \& Nikora, 2007) 
mostram que o conteúdo dos jornais se tem tornado cada vez mais uniformizado, no sentido de que os temas cobertos são semelhantes nos quatro cantos do mundo, sem o tratamento crítico de nenhum deles.

Sontag (2009) afirma que as notícias sobre a sida na década de 80 serviram muitas vezes para estigmatizar a doença e o doente, pelo que, neste sentido, talvez fosse aconselhável não ter contacto com os média para não sofrer ainda mais.

Alguns pesquisadores também encontraram problemas na formação de jornalistas, os quais podem, muitas vezes, por desconhecer termos utilizados na área médica, produzir peças sobre saúde com informações inexactas (Larsson, Oxman, Carling \& Herrin, 2003). Pettersen (2005, cit. in Hodgetts et al., 2007) associa a falta de formação técnica dos jornalistas à ausência de rigor no relato de estudos sobre saúde.

Os problemas acima descritos, no entanto, não têm de ser solucionados apenas pelos jornalistas, mas também pelos profissionais da área médica e de saúde. Entretanto, é evidente que uma melhor formação do jornalista, no sentido de desenvolver o pensamento crítico, resolveria boa parte dessas questões.

Kucinsky (2002) argumenta que o jornalismo de saúde se ressente do mesmo problema que o jornalismo em geral, que vê a notícia como uma mercadoria: “(...) quando se trata de saúde, há uma crescente mercantilização com a predominância de reportagens sobre o corpo, a beleza e os problemas de saúde que afectam as pessoas" (p.95). Para este autor brasileiro, existe, ainda, uma crise do saber jornalístico, cuja característica central é a falta de qualidade na preparação de jornalistas e no material que produzem, redundando num jornalismo medíocre. "A negação do conhecimento", diz Kucinsky (2002), “está no centro da prática jornalística” (p. 99).

Há, para além disso, um conflito entre, por um lado, profissionais e autoridades sanitárias e, por outro, jornalistas de saúde que está associado à função do jornalismo. Enquanto os primeiros vêem no jornalismo uma maneira de promover a saúde, de modo pedagógico, com a finalidade de educar o público e prevenir doenças, no campo da comunicação tem-se argumentado que essa não é a função central do jornalismo. O papel do jornalismo é dotar as pessoas de empowerment para que possam agir como plenos cidadãos.

Paralelamente ao que o jornalismo deve ser, está a percepção do jornalista sobre o que vem a ser profissionalismo. De acordo com Singer (2003), embora o jornalista se veja como alguém que possui habilidades específicas para o exercício da função, esta não é a visão do público em geral.

Neste sentido, Deuze (2005), num estudo em que tentou perceber “o que é jornalismo", conclui que as análises dos valores típicos do jornalismo, tais como os princípios da objectividade, autonomia, liberdade, expõem uma ideologia por trás do trabalho profissional do jornalismo. Os jornalistas, muitas vezes, auto-retratam-se, ainda que de uma maneira nostálgica, como trabalhadores honestos, cães de guarda (watchdogs) da sociedade, prestadores de serviço público e portadores das informações necessárias para que os indivíduos actuem de acordo com a sua própria consciência.

Para Mattos (2005), o conceito de bom profissional está ligado à incorporação de práticas responsáveis na execução das tarefas do quotidiano. "O profissional de Comunicação Social é aquele (...) que busca divulgar e estabelecer condições para a sustentabilidade da 
sociedade, estimulando o exercício da cidadania e lutando sempre pela melhoria da qualidade de vida da população e de sua saúde e em defesa do meio ambiente."

\section{Novos rumos, novas literacias}

Alguns pesquisadores, tais como Hodgetts et al. (2007) e Larson et al. (2003), têm sugerido que os jornalistas de saúde sejam treinados para basearem os seus artigos em evidências, de forma crítica, afastando-se de uma forma sensacionalista de cobertura.

Aliado a isto, as novas tecnologias de comunicação e informação, sobretudo a internet, colocam questões sobre o modo de fazer jornalismo e para quem. Independentemente de se tratar de uma revolução ou de uma evolução no campo, o facto é que o papel do jornalista enquanto gatekeeper e também enquanto mediador da informação está a ser redimensionado. Há quem defenda que se deve falar em gatewatcher. Neste sentido, o jornalista já não controla mais o acesso à informação: o controlo é exercido sobre a qualidade e o significado da mesma (Cardoso, Espanha \& Araújo, 2009).

Como tentamos argumentar, os jornalistas de saúde têm sido desafiados com uma série de questões ligadas à homogeneidade de pensamento no critério de selecção dos temas de cobertura: incompreensão e má utilização de termos técnicos empregados por profissionais de saúde e cientistas; incompreensão de como funciona o sistema de saúde e falta de uma consciência cívica e política na promoção da saúde, em nome da competitividade e do status profissional; por fim, diferença de percepção entre os profissionais da comunicação e os da saúde do que é ser jornalista.

Com vista a enquadrar os problemas acima citados numa perspectiva de responsabilização, é útil explicar o que queremos dizer com "novas literacias". Bazalgette (2008) refere-se ao termo "nova literacia" para indicar que a educação do século XXI passa pela inclusão do ensino dos novos média e através deles, não em contraposição com os meios tradicionais ou "velhos" média, mas em consonância com uma nova forma de participar da democracia.

Descrita como a capacidade de aceder, analisar, compreender e produzir diferentes tipos de média, a literacia mediática tem sido normalmente indicada para capacitar jovens. No entanto, alguns autores (Christ, 2004; Mihailidis \& Hiebert, 2005) defendem que a literacia mediática é eficaz na educação profissional e na educação superior. Isto porque, enquanto o ensino profissional se direcciona para um programa específico, a literacia mediática põe o foco na cidadania.

Christ (2004) exibe, portanto, uma concordância com o conceito de literacia mediática utilizado pela NCA (National Communication Association) norte-americana, para a qual "um comunicador média-alfabetizado deve demonstrar entendimento de como as pessoas utilizam os média no seu dia-a-dia, do complexo relacionamento entre as audiências e os conteúdos de média, do contexto em que tal conteúdo é difundido e da habilidade para comunicar com certos tipos de público" (p. 95).

Mihailidis \& Hiebert (2005) afirmam que, embora o ensino do jornalismo se tenha pautado pela diferença entre as boas e as más práticas jornalísticas e pelo modo como os média funcionam na sociedade, a literacia mediática pode oferecer uma nova dinâmica, 
ao preparar estudantes para se tornarem formadores de opinião mais críticos e mais activamente participantes.

Assim, no âmbito do jornalismo de saúde, novas literacias implicam não apenas reconhecer as mudanças que os novos média impuseram, mas o engajamento naquilo que Hodgetts et al. (2007) chamaram de jornalismo cívico-orientado. Por outras palavras, uma prática profissional assente no modelo "jornalismo de conversação”, no qual o jornalista não é apenas um observador destacado da sociedade, como no modelo “jornalismo de informação", mas actua como parte desta mesma sociedade. A ênfase do jornalismo cívico-orientado, tal como resumem Hodgetts et al. (2007), é colocada no debate público das questões de saúde entre os vários grupos de cidadãos, retirando do jornalismo de saúde a noção de que ele serve apenas ao capital.

Convém também retomarmos o conceito de literacia da saúde, usado mais acima neste texto para conceptualizar comunicação em saúde. O Centro Europeu de Prevenção e Controle de Doenças define-a como a capacidade que cada indivíduo tem para aceder e usar efectivamente as informações relacionadas com a saúde.

No modelo expandido de literacia da saúde defendido por Zarcadoolas, Pleasent \& Greer (2005), para a compreensão dos conteúdos de saúde é essencial a aquisição de multiliteracias: a literacia fundamental (saber ler e escrever e fazer operações simples de matemática), a literacia científica, a literacia cívica e a literacia cultural.

A literacia científica é vista como necessária para aumentar o conhecimento sobre o processo científico. Compreender não apenas os termos técnicos, mas a natureza incerta da ciência poderia influenciar o modo como o jornalista de saúde escolhe e dá sequência nas reportagens neste âmbito.

Porque a comunicação da saúde é um campo permanente de tensão entre a informação e a emoção, e porque também o jornalismo de saúde, como argumentámos, se tem aproximado cada vez mais da linguagem emocional, seria útil acrescentar ao referido modelo a literacia emocional, que se define pelo entendimento que temos das nossas próprias emoções e das dos outros, com o objectivo de melhorar a comunicação humana. E, ainda, dadas as transformações impostas pelas novas tecnologias de comunicação e informação no jornalismo em geral, e no jornalismo de saúde em particular, a literacia mediática apresenta-se como incontornável na formação de qualquer profissional, particularmente o de comunicação.

Não é possível, nos dias que correm, ter acesso às principais fontes de informação em saúde, às leis, eventos e estudos neste âmbito, se o jornalista responsável por cobrir esta temática não for capaz de aceder aos conteúdos digitais e distinguir aquilo que é de interesse público daquilo que, pelo contrário, apenas satisfaz os interesses da grande indústria dos cuidados de saúde (farmacêuticas, hospitais e clínicas privados, etc.) e das próprias organizações mediáticas.

O jornalista que cobre saúde é, em última análise, responsável pelo conteúdo que publica. O código genético das notícias de saúde trazem, para além da informação neste campo, as impressões e idiossincrasias dos seus jornalistas, editores, escritores e apresentadores (Johnson, 1998). Por isso é necessário estarmos atentos à realidade para que se olha, quando a saúde e a medicina estão em pauta. 
Tal como argumentam Hinnant \& Len-Rios (2009), o objectivo por trás da literacia de saúde, numa sociedade democrática, é habilitar as pessoas a participarem mais activamente das discussões públicas de saúde e ajudá-las a tomar decisões pessoais relativamente à própria saúde. E, portanto, “apoiar os princípios democráticos é um objectivo comum entre aqueles engajados com a literacia da saúde, o entendimento público de ciência e o jornalismo" (p. 91).

Hinnant \& Len-Rios (2009) defendem que conhecer a perspectiva do jornalista que cobre saúde sobre literacia é útil, em primeiro lugar, para conhecer quanto de informação sobre literacia da saúde tem sido difundida na área da comunicação em saúde e, depois, porque o jornalista desempenha o seu trabalho não sob conhecimentos teóricos de ciência, mas sob o conhecimento tácito de questões científicas. Nas entrevistas que fizeram com jornalistas de saúde sobre a percepção que estes tinham sobre literacia da saúde, os autores concluíram, para além de outros resultados, que o nível de conhecimento de saúde dos leitores é invocado pelos jornalistas de saúde para definir o conceito de literacia de saúde.

Tendo estabelecido, ao longo deste ensaio, algumas particularidades entre três áreas bastante próximas no campo social - jornalismo, comunicação e literacia -, será também útil tentar perceber como o público do jornalismo de saúde é afectado pelo conhecimento que o jornalista tem para comunicar a saúde.

\section{Jornalismo de saúde como ferramenta de empowerment do cidadão comum}

O conhecimento científico fornece um quadro sobre como a concepção jornalística da literacia de saúde do leitor influencia as suas práticas (Hinnant \& Len-Rios, 2009). Será, no entanto, que a literacia do leitor é proporcional à do jornalista? Como a literacia do jornalista contribui para formar o público? Embora essas sejam questões para um outro ensaio, tentaremos respondê-las nesta quarta parte.

Especialmente nos EUA e na Europa, onde existe uma vasta cultura mediática, os meios de comunicação social podem ter um enorme impacto no comportamento de saúde das pessoas (Schiavo, 2007: 133).

No que diz respeito ao jornalismo, em particular, as pesquisas revelam que, depois do seu médico de família, os média impressos são a segunda fonte de informação em saúde em que as pessoas mais confiam (Stuttaford, 2007).

Embora desconhecidos na sua intensidade, os efeitos dos média sobre os consumidores têm sido associados de diversas maneiras aos resultados de saúde, com graves consequências ao nível individual e da saúde pública. Isso porque nem todas as pessoas conseguem entender o que está por trás das informações mediáticas de saúde e tomar a decisão certa com base nesse entendimento. De acordo com o documento norte-americano Healthy People $2010^{5}$, nove entre dez adultos norte-americanos têm dificuldades

\footnotetext{
${ }^{5}$ O relatório Healthy People 2010é um conjunto de objectivos e metas relativamente às questões de saúde, que foi elaborado pelo Departamento de Saúde dos Estados Unidos, com a participação cidadã, no início da década, e que pode ser acedido em www.healthypeople.gov. Já há uma nova publicação - Healthy People 2020 - que pode ser acedida através do mesmo site.
} 
em utilizar correctamente as informações de saúde disponíveis todos os dias na comunidade, nos estabelecimentos de saúde e nos média.

O nível de literacia das pessoas tem sido amplamente ligado aos resultados de saúde. A literacia mediática, neste sentido, é citada por estudiosos e planeadores de campanhas de saúde como uma das estratégias importantes na comunicação da saúde, pois ela habilita pessoas de todas as idades a analisar criticamente as mensagens mediáticas, ajudando-as a entender o conteúdo dos média como construções da realidade, para além de as capacitar para a criação de mensagens e comunicação em diversos meios e plataformas (Nutbeam, 2000; Ratzan, 2001).

Como já referimos, alguns pesquisadores têm encontrado algum desequilíbrio nas notícias de saúde, sem que se avente uma solução possível. De um lado estão aqueles que defendem a preservação do conhecimento científico e consideram os leitores muito letrados, do outro estão aqueles que defendem que a informação de saúde deve ser acessível e consideram os leitores pouco letrados. Para além disso, a percepção do jornalista de saúde é a de que um dos seus papéis é aumentar a literacia que as pessoas têm sobre saúde (Hinnant \& Len-Rios, 2009).

Zarcadoolas et al. (2005), ao analisarem as notícias sobre a contaminação por antraz nos Estados Unidos, descobriram que a baixa literacia combinada com mensagens pobres de saúde veiculadas nos média resultam na recusa por parte de alguns cidadãos em seguir as orientações de saúde pública.

Como vimos, os estudos sugerem que o fortalecimento do jornalismo de saúde resultaria também no fortalecimento da literacia dos cidadãos comuns.

\section{Conclusão}

A globalização trouxe novos desafios para o jornalismo de saúde, impondo-lhes a aquisição de competências essenciais para o exercício da profissão. Não é possível pensar o jornalismo de hoje sem a incorporação das novas tecnologias, que alteraram de maneira significativa o modo de fazer jornalismo.

No jornalismo de saúde estes avanços significaram o início de um processo de desintermediação (Pinto, 2005) entre o jornalista de saúde e o público leigo, no sentido de que ele não é mais o único a mediar as informações nesta área, colocando em xeque o seu papel como "corrector das informações de saúde" (Hinnant \& Len-Rios, 2009).

Algumas críticas quanto à formação do jornalista de saúde têm sido tecidas por pesquisadores, profissionais e autoridades de saúde sobre o desempenho da profissão e falta de preparação para actuar na cobertura de notícias médicas e de saúde. A impossibilidade de controlar a qualidade do conteúdo jornalístico publicado tem levado a um afastamento do jornalismo de saúde como estratégia para a comunicação de saúde, no sentido de a promover.

Coloca-se, neste sentido, a necessidade de treinar os jornalistas para que actuem de forma crítica e responsável. Alguns estudos têm provado que a literacia do jornalista, nomeadamente no campo da saúde, contribui para aumentar a literacia do público neste campo. 
Parece-nos, diante deste contexto, que o jornalista de saúde precisa de adquirir novas competências para comunicar a saúde, no sentido de dar informações neste âmbito, tanto para assegurar a continuidade da sua função como "corrector das informações de saúde" e executá-la com rigor, como para controlar a qualidade do conteúdo produzido, com o objectivo de aumentar também a literacia do seu público.

\section{Referências}

Azevedo, A. P. M. (2009). Jornalismo em Saúde: Uma visão transcontinental. Universidade do Minho, Braga. Bazalgette, C. (2008). New Literacy, New Democracy. Retrieved. from http://www.beyondcurrenthorizons. org.uk/wp-content/uploads/bch_challenge_paper_democracies_cary_bazalgette.pdf.

Berridge, V. (2007). Marketing Health: Smoking and the discuourse of public health in Britain. New York: Oxford University Press Inc.

Cardoso, G.; Espanha, R. \& Araújo, V. (eds.). (2009). Da Comunicação de Massa à Comunicação em Rede. Porto: Porto Editora.

Christ, W. G. (2004). Assessment, media literacy standards, and Higher Education. American Behavioral Scientist, 48(1), 92-96.

Deuze, M. (2005). What is journalism? Journalism, 6(4), 442-464.

Favereau, É. (2005). Le journalisme, de l'information médicale à l'information santé. Sève, hiver(9), 21-26.

Flora, J. A.; Maibach, E. W. \& Maccoby, N. (1989). The role of media across four levels of health promotion intervention. Annual Review of Public Health, 10(1), 181-201.

G1. (2010). Cobertura completa: terremoto no Haiti. Tremor de magnitude 7 no dia 12 matou 200 mil. G1 from http://g1.globo.com/Noticias/Mundo/0,,MUL1446514-5602,00-COBERTURA+COMPLETA+TE RREMOTO+NO+HAITI.html

Ginman, M. (2000). Health information and quality of life. Health Informatics Journal, 6(4), 181-188.

Hijmans, E.; Pleijter, A. \& Wester, F. (2003). Covering scientific research in Dutch newspapers. Science Communication, 25(2), 153-176.

Hinnant, A. \& Len-Rios, M. E. (2009). Tacit understandings of health literacy. Science Communication, 31(1), 84-115.

Hodgetts, D.; Chamberlain, K.; Scammel, M.; Karapu, R. \& Nikora, L. W. (2007). Constructing health news: possibilities for a civic-oriented journalism. Health, 12(1), 43-66.

Johnson, T. (1998). Medicine and the media. New England Journal for Medicine, 339(2), 87-92.

Kuscinsky, B. (2002). Jornalismo e saúde na era neoliberal. Saúde e Sociedade, 11(1), 95-103.

Larsson, A.; Oxman, A. D.; Carling, C. \& Herrin, J. (2003). Medical messages in the media - barriers and solutions to improving medical journalism. Health Expectations, 6(4), 323-331.

Mattos, S. (2005). Ética na Mídia e na Saúde. Paper presented at the I Ciclo de Mídia e Saúde Pública no Brasil. from http://metasigma.multiply.com/journal/item/26/26

McQuail, D. (2003). Teoria da Comunicação de Massas. Lisboa: Fundação Calouste Gulbenkian.

Mihailidis, P. \& Hiebert, R. (2005). Media literacy in journalism education curriculum. Academic Exchange Quartely, 9(3).

Nelkin, D. (1996). An uneasy relationship: the tensions between medicine and the media. Lancet, 8, 1600-1603.

Niederdeppe, J.; Farrelly, M. C.; Thomas, K. Y.; Wenter, D. \& Weitzenkamp, D. (2007). Newspaper coverage as indirect effects of a health communication intervention: The Florida Tobacco Control Program and youth smoking. Communication Research, 34(4), 382-405.

Nutbeam, D. (2000). Health literacy as a public health goal: a challenge for contemporary health education and communication strategies into the 21st century. Health Promotion International, 15(3), $259-267$.

Pellechia, M. G. (1997). Trends in science coverage: A content analysis of three US newspapers. Public Understanding of Science, 6(1), 49-68.

Pinto, M. (2004). Ventos Cruzados sobre o Campo Jornalístico. Percepções de profissionais sobre as mudanças em curso. Paper presented at the Actas do II Encontro Ibérico de Ciências da Comunicação Universidade da Beira Interior.

Ratzan, S. C. (2001). Health literacy: communication for the public good. Health Promot. Int., 16(2), 207-214.

Schiavo, R. (2007). Health Communication: From theory to practice. São Francisco (CA): Jossey-Bass. 
Seale, C. (ed.). (2002). Media \& Health. London: Sage.

Shuchman, M. \& Wilkes, M. S. (1997). Medical scientists and health news reporting: a case of miscommunication. Annals of Internal Medicine, 126(12), 976-982.

Shwitzer, G. (2008). How do US journalists cover treatments, tests, products, and procedures? An evaluation of 500 stories. Plos Medicine, 5(5), 700-704.

A Sociedade da Informação em Portugal. (2010). Retrieved. from http://rcbp.dglb.pt/pt/ServProf/ S\%EDtios\%FAteis/SociedadedoConhecimento/Documents/A_Sociedade\%20de\%20Informa\%E7\%E3o em_PT_doc_trabalho_Maio_2010.pdf.

Sontag, S. (2009). A Doença como Metáfora. Lisboa: Quetzal Editores.

Stuttaford, T. (2007). The influence of print media on their readers' understanding of the benefits of moderate drinking. Annals of Epidemiology, 17(5, Supplement 1), S108-S109.

Thomas, R. K. (2006). Health Communication. New York: Springer Science.

Thompson, T. L., Dorsey, A. M.; Miller, K. I. \& Parrott, R. (2003). Handbook of Health Communication. New Jersey: Lawrence Erimbaum Associates, Inc.

Zarcadoolas, C.; Pleasant, A. \& Greer, D. S. (2005). Understanding health literacy: an expanded model. Health Promot. Int., 20(2), 195-203. 